\title{
Review \\ Framework for Design of Sustainable Flexible Pavement
}

\author{
Enyew Asres ${ }^{1, *}$, Tewodros Ghebrab ${ }^{2}$ ad and Stephen Ekwaro-Osire ${ }^{3}(\mathbb{D}$ \\ 1 Department of Civil Engineering, Jimma Institute of Technology, Jimma 378, Ethiopia \\ 2 Department of Civil, Environmental \& Construction Engineering, Texas Tech University, \\ Lubbock, TX 79409, USA; Tewodros.ghebrab@ttu.edu \\ 3 Department of Mechanical Engineering, Texas Tech University, Lubbock, TX 79409, USA; \\ Stephen.ekwaro-osire@ttu.edu \\ * Correspondence: eny0407@ddu.edu.et
}

check for updates

Citation: Asres, E.; Ghebrab, T.; Ekwaro-Osire, S. Framework for Design of Sustainable Flexible

Pavement. Infrastructures 2022, 7, 6. https://doi.org/10.3390/

infrastructures7010006

Academic Editor:

Tatiana García-Segura

Received: 22 October 2021

Accepted: 16 December 2021

Published: 31 December 2021

Publisher's Note: MDPI stays neutral with regard to jurisdictional claims in published maps and institutional affiliations.

Copyright: (C) 2021 by the authors. Licensee MDPI, Basel, Switzerland. This article is an open access article distributed under the terms and conditions of the Creative Commons Attribution (CC BY) license (https:// creativecommons.org/licenses/by/ $4.0 /)$.

\begin{abstract}
The conventional methodologies for the design of flexible pavements are not adequate in providing solutions that meet the diverse sustainability challenges. Therefore, developing new methodologies and frameworks for the design of flexible pavement has become a priority for most highway agencies. On the other hand, there is no sound sustainable flexible pavement framework at the design phase that considers the key engineering performance, environmental impact, and economic benefits of sustainability metrics. Hence, premature failure of flexible pavements has become a common problem leading to a growing demand for sustainable pavement. Pavement engineers need to have access to tools that permit them to design flexible pavements capable of providing sustainable solutions under various complex scenarios and uncertainties. Hence, the objective of this study was to develop a resilience analysis framework, probabilistic life cycle assessment (PLCA) framework, and probabilistic life cycle cost analysis (LCCA) framework as the pillars of sustainability. These frameworks were used to develop a single sustainable flexible pavement design framework. The developed framework enables highway agencies to effectively quantify the lifetime sustainability performance of flexible pavements during the design phase in terms of resilience, environmental sustainability, and economic sustainability; and it allows to select the optimum design by comparing alternative design options. The framework will enhance the durability of flexible pavement projects by minimizing the cost, operational disturbance, environmental impact, and supporting the design. Many countries, especially those that fully dependent on the road network as the primary transportation route, may benefit from the sustainability-based road network design, which could ensure dependable market accessibility. The resilience of such a road network may reduce the cost of business activities by minimizing the interruption in surface transportation due to the functional and structural failures resulting from extreme events.
\end{abstract}

Keywords: sustainability; resilience; life-cycle assessment; life-cycle cost analysis; flexible pavement; uncertainties

\section{Introduction}

Flexible pavements are one of the vital gears of transportation systems [1] that sustain socio-economic growth for a nation [2]. However, their construction and preservation require large capital investment [3]. Thus, ensuring sustainable flexible pavements [4] has become a primary focus of flexible pavement management systems and highway agencies [5]. Fundamentally, pavement sustainability is a complex and broad concept [6] that can be evaluated by analyzing three pillars: the environmental, performance, and economic sustainability of the system [2]. Environmental sustainability evaluation tools were developed to quantify the environmental impacts of pavement [7]; economic sustainability tools were designed to evaluate the monetary influence of possible modifications in design, construction, and materials; and resilience evaluation approaches were developed to evaluate the sustainability levels of engineering performance of the system holistically [8]. Application of green technology [9], recycling and reuse of materials, and utilization of locally available 
materials contribute to sustainable pavement [8]. Generally, pavement sustainability is a non-tradeoff balance between engineering performances, the least possible environmental impacts, and economic benefits aspect to pavement assets [10]. Sustainability-driven systems need to be environmentally helpful as well as economical [11]. Sustainability of flexible pavements throughout the design lifetime, under the rare but damaging severe environmental events, needs to be addressed at the design stage based on resilience, LCA, and LCCA.

The resilience triangle [12], a hybrid bottom-up/top-down adaptation [13], and Bayesian network [14] approaches were used to assess the infrastructure performance and quantify the resilience of the system during normal and extreme event conditions. LCA framework has been established to calculate energy consumption and greenhouse gases (GHG) emission during material production [15]. LCA and Mechanistic-Empirical Pavement Design Guide (MEPDG) integrated framework has been developed to support an inventory analysis [1]. The MEPDG helps in performing LCCA [1]. Uncertainties associated with model parameters, measurement variabilities, traffic growth, and the changes in the pavement IRI with time were evaluated using the probabilistic LCCA approach [16]. LCCA model was established to quantify the impact of pavement preservation on the cost of agency and vehicle operation [17]. Fundamentally, LCCA is a decision-support tool applied by highway agencies to compare the overall cost of alternative projects [18-20].

The available sustainability technology is very limited to satisfactorily assess the environmental and economic impacts and engineering performance of asphalt mixtures and waste, recycled, and reused materials [10]. The resilience triangle approach is not properly structured and complex to quantify the resilience metrics of the system [12]. Further, there is significant variation from the available resilience prediction models in terms of the magnitude of resilience metrics [21]. The LCA framework uses limited information in the early design phase of roads to evaluate their environmental impacts [22] because it is difficult to acquire the data necessary to carry out LCA leading to the final design. Lack of transparency and homogeneity of the data used by several researchers for the design and LCA features of pavement has also been the barrier for a harmonized application of LCA [23]. In other words, the choice of LCA methodology varies with the type of study [24]. Thus, by adjusting these inconsistencies, an environmentally friendly asphalt technology could be recognized [23]. Frequently, experts get challenged by substantial uncertainties in estimating the short-term and long-term costs [25]. A framework needs to be developed to quantify the sustainability of flexible pavements and their design alternatives by analyzing the environmental and economic impacts of the pavements [7].

The term sustainability started to get due attention around 1972 [26] and applies to every aspect of life. Sustainability is defined in terms of the system's capacity to maintain natural laws and human values in the long-term future. Sustainable criteria need to be integrated into policies and strategies at every stage of the development process with the entire life cycle of a system. Thus, it has become the main focus of modern infrastructure design. Similarly, sustainable pavement can be defined as a pavement that pleased long-life engineering reliability, with a minimum acceptable life cycle economics and environmental impacts. The need to minimize the use of scarce primary resources is becoming more urgent in the pavement industry [27]. Thus, sustainable pavement design is based on some criteria, such as minimizing reliance on natural resources, reducing energy consumption and GHG emissions, limiting air, water, and noise pollution, and improving health, safety, risk prevention, and user comfort [28]. Applying sustainability definition to the construction field could result in a set of processes by which a profitable and competitive industry delivers buildings, structures, and roads that improve the quality of life while maximizing the efficient use of natural resources and energy [29]. Several studies have been conducted to evaluate the sustainability of pavements in terms of life cycle costs and/or environmental impacts [30]. However, sustainable practices in civil infrastructure, especially in pavement engineering, are emerging concepts but slow to be applied, likely due to (a) policy and decision-makers have not been provided with the key pieces of the broad knowledge that 
need to make expert decisions, and (b) there is a deficit of definite sustainability assessment metrics [31]. Sustainable pavement design procedure starts by defining the goals, benefits, requirements, and methods and identifying the key sustainability performance indicators and standard index of the pavement [32]. Though the practice of sustainable design in pavement projects started before 2015 , study reports indicate that the topic started to get more attention in the years closer to 2015. Based on these observations, the authors believe that, in addition to current developments in sustainable flexible pavement design, most of the research findings reported before 2015 would likely be referenced in the recent publications. Hence, this paper has relied on the reports of peer-reviewed research papers on various aspects of pavement sustainability published between 2015 and 2020.

The concept of sustainability is a multi-disciplinary, broad, and complex topic that touches almost every field of practice [6]. In the field of transportation infrastructure, sustainability must be at the core of every activity from the initial planning to the final phase of the construction of the structural system. To ensure a sustainable infrastructure system, a well-designed and smart approach is imperative. The lack of a standard framework for evaluating sustainability, particularly in highway structures [15], and globally acceptable sustainability metrics [33] has been a hindrance. Thus, acceptable sustainability assessment tools are needed to balance the performance, economic, and environmental sustainability of pavement systems [7].

Inconsistencies in the source and quality of data and issues [34], lack of standardized procedure of conducting LCAs on pavements, and failure to consider the time effect of environmental impacts in pavement designs have delayed the adoption of LCA frameworks by the decision-makers [35]. Lack of dynamic user traffic patterns, local and region-specific data resources, assumed data (based on relevant literature) or calculated data is a serious challenge in the application of LCA frameworks in both research and industry projects [34]. Furthermore, inconsistent and inappropriate LCA in terms of the functional unit, reference service life, system boundary, lifecycle inventory, limited reporting of data sources, and lack of sensitivity and uncertainty analyses pose serious challenges in identifying the most environmentally friendly flexible pavement technology $[35,36]$.

In this study, a framework for the design of sustainable flexible pavement was developed by combining probabilistic LCCA (PLCCA), probabilistic LCA (PLCA), and resilience into one single framework. The resulting framework can be used by pavement engineers as a guide to compare alternative design options by combining PLCCA, PLCA, and resilience analysis (RA) and selecting the optimum design option based on the evaluation criteria. The framework can be adopted to conduct regional and national planning of highway transportation networks as a part of countrywide sustainability goals.

From the above statement, the following research question was developed: can a framework for use at the design phase of a sustainable flexible pavement be developed? To answer this research question, four objectives were outlined, namely:

1. Develop a resilience analysis, probabilistic life cycle assessment, and life cycle cost analysis frameworks,

2. Construct a sustainability framework using the results of the above objectives.

The study focused on developing a framework for a comprehensive sustainable flexible pavement. To develop the framework, first RA, LCA, and LCCA concepts and their quantification techniques in flexible pavement design were considered. The technique could help in alleviating the problems due to resource scarcity and the challenges to road authorities from the environmental impacts of pavements. It satisfies the engineering constraints before and after extreme event occurrences. Then, the individual generic frameworks for PLCA, PLCCA, and RA were developed. Finally, the comprehensive sustainable framework for flexible pavements was developed by integrating the three components of the sustainable performance assessment tools. 


\section{Materials and Methods}

Literature review articles are classified into nine categories based on their aims, namely narrative, descriptive, scoping, critical, meta-analysis, qualitative systematic, umbrella, theory development, and realist reviews [37]. Meta-analysis was selected as the best fit for this research study. The PRISMA principles were used for the meta-analysis to develop a sustainable framework for flexible pavement design by integrating resilience, PLCA, and probabilistic PLCCA into a single comprehensive framework.

The search process was started by identifying articles relevant to the topic of interest using keywords. The search was limited to reliable materials from the leading peerreviewed journals $[37,38]$. Sustainable flexible pavement, resilient pavement, pavement life cycle assessment, and pavement life cycle cost analysis were the keywords used during the search process to retrieve the pertinent articles for the literature review.

The articles considered in this research were limited to those published between 2015 and 2020. The search engines used included Google, Web of Science, Science Direct, and Google Scholar [37].

The criteria used to select the most relevant articles to the research are shown in Table 1. The included articles were reviewed with regards to sustainability definition, resilience definition, sustainability indicators, metric tools, environmental impacts, probabilistic LCA, LCA methodological frameworks, probabilistic LCCA, and LCCA methodological frameworks.

Table 1. Inclusion and exclusion criteria.

\begin{tabular}{cccc}
\hline $\begin{array}{c}\text { Inclusion } \\
\text { and } \\
\text { Exclusion }\end{array}$ & Criteria & Details & Justification \\
\hline Exclusion & $\begin{array}{c}\text { Search } \\
\text { Engine } \\
\text { results }\end{array}$ & $\begin{array}{c}\text { Rigid } \\
\text { pavement }\end{array}$ & Has different characteristics and performance \\
\hline & Less related & Do not provide detailed information specific to \\
the study
\end{tabular}

The total number of articles identified at the outset was 1787, in which 981 on sustainability and pavement, 472 on LCA and pavement, 278 on LCCA and pavement, and 146 on resilience and pavement keyword containing articles. After running a check for duplication, title irrelevance, and unavailability of attached full text, 981 were excluded. A total of 91 references were used to answer the research questions. The article selection strategy followed to perform a systematic literature review is shown in Figure 1.

From the intensive literature review, no reports on the availability of comprehensive tools for the implementation of the concepts of sustainability in pavement design were found. Hence, the conventional pavement design methodologies are not adequate to provide solutions to the diverse pavement sustainability challenges. To address this challenge, it is imperative to develop a comprehensive sustainable flexible pavement framework. The first intensive literature review was carried out on the tools for the implementation of sustainability concepts in pavement design. This helped to identify the gaps in the conventional pavement design methodologies. To address the gaps, a generic framework for resilience analysis, probabilistic life cycle assessment, and probabilistic life cycle cost 
analysis frameworks were developed independently. Finally, these individual frameworks were assembled into a single framework to establish a comprehensive sustainable flexible pavement framework capable of evaluating the sustainability of a flexible pavement at its design phase.

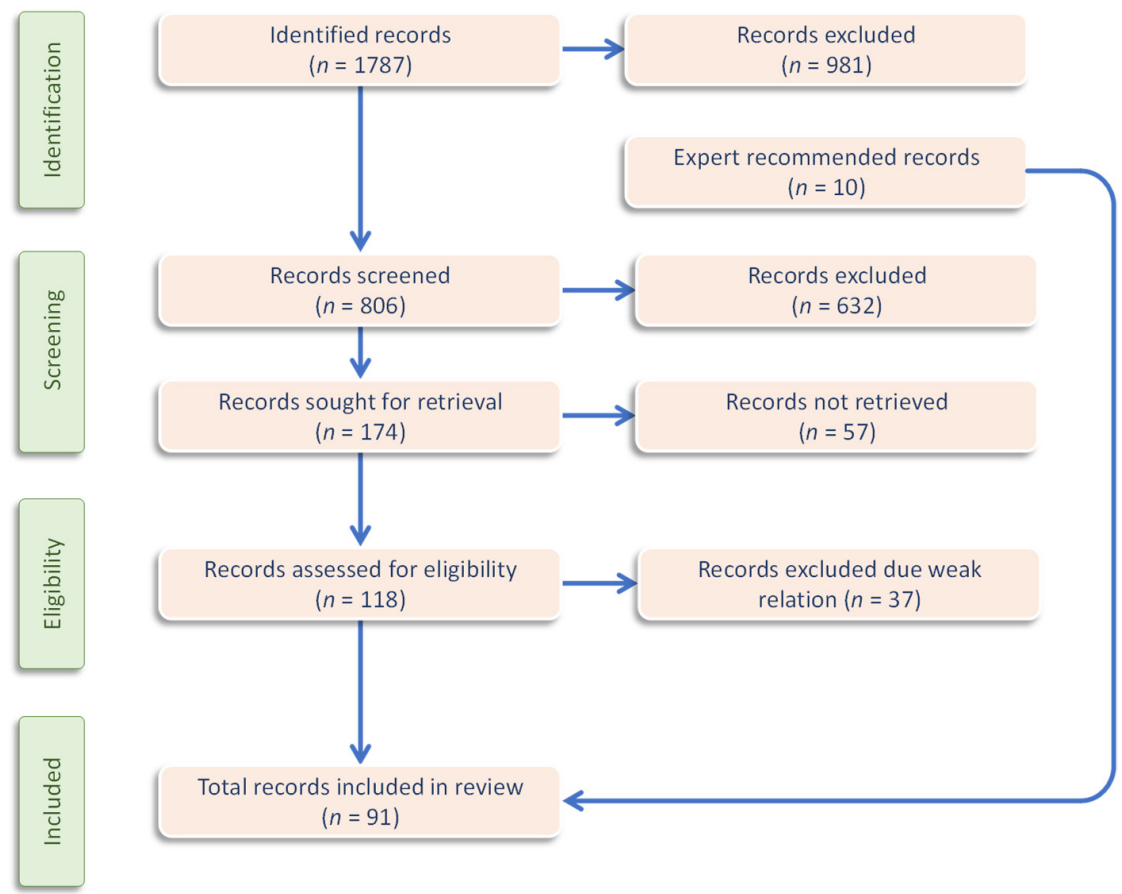

Figure 1. Preferred reporting items for systematic reviews and meta-analyses process.

\section{Results}

\subsection{Resilience Framework}

The concept of resilience assessment of infrastructures was developed to understand the performance behavior of infrastructure during and after it has been subjected to extreme disturbance events [39]. Resilience focuses on the dynamic nature of systems and their ability to function under a shock without undergoing an irreversible or unacceptable decline in their structural integrity and functionality [40]. When a resilient system is subjected to a rarely occurring extreme damaging event, it will either withstand the event or recover from any damage it sustains from the less likely occurrence of extreme events. In the USA, for example, the National Infrastructure Advisory Council defines infrastructure resilience as the ability to reduce the magnitude and/or duration of disruptive events [41]. Further, the Multi-disciplinary Center for Earthquake Engineering Research at Buffalo includes robustness, redundancy, resourcefulness, and rapidity as characteristics of resilience [12]. The resilience of the infrastructure system is a crucial attribute that has gained much attention within the engineering discipline [42]. Therefore, research on system resilience for critical infrastructure has significantly increased, and quantification of resilience has become the major factor to sustain infrastructure system functionality [43].

Resilience metrics are used to measure the sustainability and recovery potential of a system [44]. Several attempts have been made to define and explain resilience metrics used to judge the influence of investment and policy decision-makers in the selection of the best resilience system [40]. Resilience can be characterized by the so-called four Rs of resilience metrics. These are:

- $\quad$ Robustness: the capacity of a system and parts of the system to repel extreme event impacts without sustaining significant performance damage,

- Redundancy: the degree of a system and parts of the system to sustain defined functional requirements in the event of a disturbance, 
- Resourcefulness: the facility to recognize and prioritize harms and mitigation reaction, and monitoring economic, technical, and performance-related problems,

- Rapidity: the ability of a system and parts of the system to recover losses and avoid future disruptions [12].

RA is an advanced technique of modeling that predicts the pavement structural conditions and acts proactively to maintain pavement infrastructure functionality [45]. RA is a new, innovative, and flexible scientific-engineering procedure used to develop tailorable validated methods that can conceptualize, design, assess, and generate metrics for improved system resilience. This earned RA wide attention from academia as well as the industry [19]. Theoretically, RA is held in a mindset of reducing failure probabilities, consequences, and recovery time during the occurrence of disturbances [42]. Thus, infrastructure investments based on RA are used to reduce the impacts of current and future climate risks [46] through situation assessment, rapid response, and effective recovery strategies [47]. Extreme and prolonged moisture is the most common hydrological extreme phenomenon that causes inconvenience and widespread damage to the pavement. Continuous high-temperature variations can cause severe damage to the flexible pavement due to alternate softening and hardening of the asphalt surface, which can result in rutting and thermal cracking [48]. Extreme weather events, such as heavy rainfall, flooding, and heatwaves can cause severe deterioration of flexible pavement $[49,50]$. To ensure the sustainability of investments over their entire lifetime, climate scientists and infrastructure engineers are engaged in the study of climate change impacts and adaptations in transportation infrastructures [51]. Identifying and incorporating climate information into engineering design is the first step in reducing climate change impact vulnerability of pavement [51,52]. To address these effects at the design stage, resilience can be analyzed using different approaches such as graph theory, optimization techniques, and simulation [14].

The resilience of flexible pavement under severe environmental events with a low probability of occurrence but the high damaging influence is a major global concern. It is difficult to accurately predict the impact of these extreme events on critical infrastructures. Further, there is no clear methodology to quantify resilience both in terms of operational and infrastructure integrity [53]. As a result, most flexible pavements were designed based on historical climate data which does not reflect the anticipated future tendencies [51]. Flexible pavement design and management practices must be adapted in response to future climate changes [54]. Existing non-resilient-engineered systems may gradually downgrade toward a low-level performance and capacity due to extremely disruptive events. Resilience engineering quantities can be used to formulate an overall resilience framework [19]. No precisely known threshold for the level of resilience of flexible pavement could be found in the literature, and it will remain a challenge to researchers unless resolved [40]. This challenge reinforces the need for metrics to evaluate flexible pavement resilience. Thus, resilience requires thinking about the potential burden on the stability of a system and could develop countermeasures or safeguard the longstanding losses [42]. Enhancing system resilience at a structure level could lead to massive savings through risk reduction and expeditious recovery. Therefore, a resilience pavement framework that can serve as a lens for sustainability has been developed to solve the existing gap. In the framework, the resilience concept and quantification techniques were considered in flexible pavement design to overcome resource insufficiency challenges for road authorities by satisfying the engineering constraints before and after extreme event occurrences. Infrastructure design engineers may apply status-quo, flexible, or robust design approaches to create a resilience system for low, gradual, and worst-case projected climate change scenarios, respectively [48]. The proposed flexible pavement resilience framework is shown in Figure 2. 


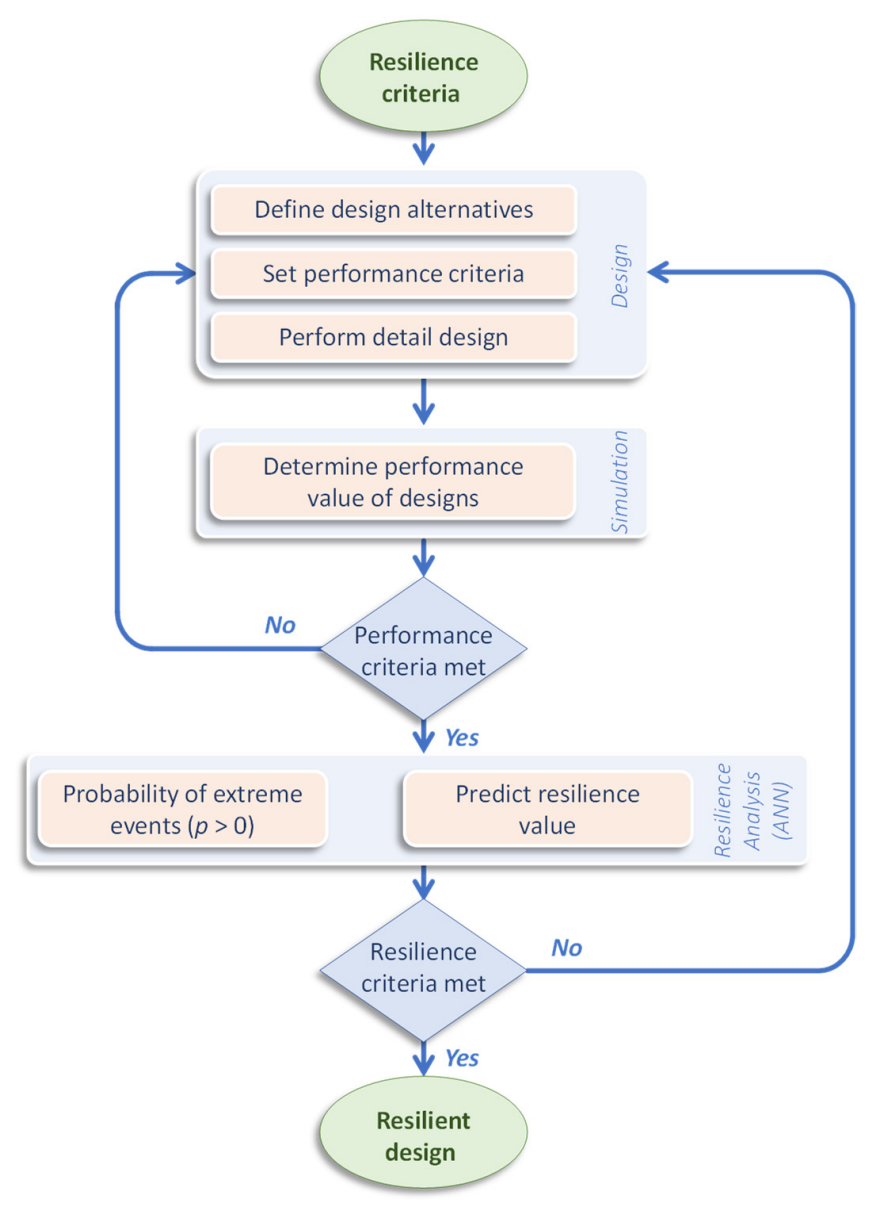

Figure 2. Flexible pavement resilience framework.

In this flexible pavement design procedure, resilience principles should be considered in advance before the reality of risk issues. Thus, resilience criteria are significant and robust for the sustainability of flexible pavement. The collective influence of climate change, augmented traffic flow burden, economic force, and community demand have impelled pavement design to take into consideration resilience criteria at the initial stage of pavement design and appraisal process. This requires integrating resilience criteria into policies, strategies, and designs at every stage of pavement development practice with the all-inclusive life cycle of the system. The resilience criteria considered in the study include:

- Identify existing and anticipated future situations to withstand the likely traffic load and environmental influence,

- Recognize the local context of susceptibility and exposure to extreme events,

- Reduce the probability of failure, consequence, and time to recover.

The number of alternative designs, design components, and design period should be defined in line with the resilience criteria. For each defined design alternative, a detailed design configuration (thickness of layers and arrangements and traffic demand) should be determined. Design alternatives and performance criteria should be selected based on mechanistic details. Pavement materials assumed to be elastic, and high resilience modulus value will be selected to achieve resilient pavement. Performance simulation should be carried out to predict the service life performance values of the design alternatives under normal condition scenarios. If the lifetime performance of the design has achieved the required design period, then the required performance is satisfied; otherwise, modify the design configurations by considering the occurrence of extreme events and the resilience level of the design using machine learning techniques (artificial neural networks). If the design satisfied the resilience criteria, then the design will be considered as a resilience 
design; otherwise, use an alternative design configuration until the residence criteria are satisfied. The level of resilience can be expressed as follows: due to the occurrence of extreme events, the probability of pavement degradation ( $p$ ) can be $p>0$ or $p=0$, where $\mathrm{p}=0$ indicates that the resilience level of the pavement can be at a robust level, whereas $\mathrm{p}>0$ indicates normal pavement functionality. The level of resilience can be considered as a redundancy if $\mathrm{p}>0$ with a slight pavement functionality damage or rapid recovery. Otherwise, $\mathrm{p}>0$ with a major pavement functionality damage that needs maintenance $(\mathrm{M})$, the resilience level is considered as resourceful and may require to be redesigned.

From Table 2, rest periods recovery, resilience properties and triangle, and agent-based and scenario-based frameworks are used to demonstrate the resilience of systems. Bio retention and anti-stripping materials can enhance the resilience properties of the system. Recurrent neural models and moisture damage models are used to evaluate the resilience performance of the systems.

Table 2. Resilience framework, performance model and metrics, stressors, and resilience additive materials.

\begin{tabular}{cccccc}
\hline Framework & $\begin{array}{c}\text { Performance } \\
\text { Model }\end{array}$ & Stressor & $\begin{array}{c}\text { Resilience } \\
\text { Metrics }\end{array}$ & $\begin{array}{c}\text { Resilience } \\
\text { Additive } \\
\text { Material }\end{array}$ & References \\
\hline $\begin{array}{c}\text { Rest } \\
\text { periods } \\
\text { recovery }\end{array}$ & $\begin{array}{c}\text { Recurrent } \\
\text { Neural } \\
\text { networks }\end{array}$ & $\begin{array}{c}\text { Freeze-thaw } \\
\text { cycles }\end{array}$ & Recovery & Bioretention & [55] \\
\hline $\begin{array}{c}\text { Resilience } \\
\text { properties } \\
\text { and } \\
\text { triangle }\end{array}$ & $\begin{array}{c}\text { Moisture } \\
\text { damage }\end{array}$ & - & $\begin{array}{c}\text { Robustness, } \\
\text { redundancy, } \\
\text { resourcefulness, } \\
\text { and rapidity to } \\
\text { recovery }\end{array}$ & $\begin{array}{c}\text { Anti- } \\
\text { stripping }\end{array}$ & [12] \\
\hline $\begin{array}{c}\text { Asset- } \\
\text { based and } \\
\text { scenario- } \\
\text { based }\end{array}$ & - & $\begin{array}{c}\text { Recovery index } \\
\text { and lifetime } \\
\text { climate } \\
\text { sensitivity }\end{array}$ & \\
\hline
\end{tabular}

Artificial neuronal networks (ANN) should be used to predict pavement performance conditions. Because of its powerful computational tool to analyze complex multi-layered structures and different evaluation parameters, the resilience level of the system could be assessed using the artificial neuronal network simulation technique [56].

The resilience framework considers the effect of traffic loads, climate conditions, and extreme weather events. The resilience and vulnerability of a pavement system should be defined, in line with the framework, to get a better and more efficient decision tool that could enable the highway agencies to accurately measure the comparative levels of pavement resilience. Especially landlocked countries with a few navigable rivers could benefit more from the resilience-based road network design. This approach could ensure secure market accessibility and stable business interactions in the countries without interruption of surface transportation caused by pavement failures from extreme events. Resilience is an indispensable part of pavement design. Since climate will continue to change, it needs to integrate climate change into pavement design by considering a generic resilience pavement framework. To achieve resilient infrastructural systems, time-dependent dynamic system decisions should be considered. Thus, pavements must be designed in a way to withstand and or recover quickly from damages sustained during extreme events. According to Singhal et al. [57], the resilience value of a flexible pavement for each uncertainty of extreme events is formulated as

$$
R_{a}(t)=\frac{1}{t_{e}-t_{0}} \int_{t_{0}}^{t_{e}} Q_{a}(t) d t
$$




$$
\begin{gathered}
Q_{a}(t)=\left\{1-L_{a}\left[H\left(t_{e}-t_{0}\right)-H\left(t_{0}+\operatorname{Tre}_{a, j}\right)\right]\right\} f_{\text {reca }} \\
L_{a}=\sum_{j=0}^{m} P_{a, j} * D_{a, j} \\
f_{\text {reca }}= \begin{cases}0 & t_{0} \leq t<\operatorname{Tr}_{a, j} \\
1 & t \geq \operatorname{Tre}_{a, j}\end{cases} \\
\operatorname{Tr}_{a}=\sum_{j=0}^{m} P_{a, j} * \operatorname{Tr}_{a, j}
\end{gathered}
$$

According to Mills et al. [58] performance can be defined by International Roughness Index (IRI)

$$
\begin{gathered}
\mathrm{IRI}=\mathrm{IRI}_{0}+0.463\left[S F\left(\text { Age } / e^{20}-1\right)\right]+0.00119\left(T C_{L}\right)_{T}+0.1834\left(C O V_{R D}\right)_{T} \\
+0.0084(F C)_{T}+0.00736(B C)_{T}+0.00155\left(L C_{S N W P}\right)_{M H}
\end{gathered}
$$

where

$R_{a}(t)$ resilience of pavement configuration $a$ at time $t$,

$Q_{a}(t)$ pavement configuration a functionality at time $t$,

$f_{\text {reca }}$ pavement configuration a recovery function,

$H$ Heaviside step function,

$D_{a, j}$ damage ratio of pavement configuration $a$ in damage state $j$,

$m$ number of damage states of pavement configuration $a$,

$P_{a, j}$ probability of failure pavement configuration $a$ in damage state $j$,

$T r e_{a, j}$ recovery time of pavement configuration $a$ in damage state $j$,

$L_{a}$ loss function,

$T r e_{a}$ recovery time for pavement configuration $a$,

$t_{0}$ time before the occurrence of event $e$,

$t_{e}$ time at which extreme event occurs,

$\mathrm{IRI}_{0}$ initial international roughness index after construction, $\mathrm{m} / \mathrm{km}$,

$S F$ sight factor,

$\left(T C_{L}\right)_{T}$ total length of transverse cracks $\mathrm{m} / \mathrm{km}$,

$\left(C O V_{R D}\right)_{T}$ rut depth coefficient of variation, percent,

$(F C)_{T}$ total area of fatigue cracking \%,

$(B C)_{T}$ total area of block cracking \%,

$\left(L C_{S N W P}\right)_{M H}$ medium and high severity sealed longitudinal cracks outside the wheel path, $\mathrm{m} / \mathrm{km}$,

Age age after construction, years.

Pavement functionality or International Roughness Index (IRI) at the design phase can be determined through the artificial neural network as indicated in Figure 2.

The functionality of a system as a variable range from $0 \%$ to $100 \%$, where $0 \%$ indicates that no service is available, while $100 \%$ indicates that there is no degradation in service. If a disruption occurs, functionality drops below $100 \%$. The service is assumed to be fully recovered when functionality gets back to $100 \%$ after recovery. Thus, resilience is expressed as an integral part of the functionality. A model for quantification of resilience against extreme event occurrence is presented by adopting functionality and loss and recovery functions from earthquake research. The recoveries from extreme disasters depend on preparedness, mitigation, response, and recovery efforts. Probabilistic numbers for a damaged structure, as a function of extreme events, called fragility curves, are incorporated into the model formulation [59].

\subsection{Life Cycle Assessment Framework}

LCA is a globally used technique in pavement engineering and the main tool for the analysis of the impact of pavements on the environment [60]. The application of LCA to pavement design and management decisions [61] presents an opportunity to reduce 
the environmental impacts of pavement [2] and promote green pavements [61]. LCA enhancement and environmental conservation awareness enforced sustainable approaches to the design and management of pavement [62]. There have been universal warnings on climate change, energy usage, environmental impacts, and financial limitation, which affect pavement [26]. Furthermore, adaptation is a global challenge that needs scientific knowledge of climate. This enhances the resilience and adaptive capacity of pavements and reduces the vulnerability of the system to climate change through sustainable management of natural resources intending to ensure sustainable development [63]. LCA is a suitable tool that can support designers to deal with the environmental aspects of pavements and realize sustainable pavements [64]. Thus, policy-makers in the transportation sector have shown a growing interest in the application of LCA tools at the early stage of flexible pavement design to reduce its impacts on the environment [65]. LCA tools should be considered during pavement design, procurement, building, and maintenance routine to assess the sustainability of various choices [15].

LCA tools are used to select various technologies which could reduce construction and maintenance-related impacts of the pavements [62]. By adopting appropriate LCA tools, pavement designers can achieve more sustainable pavement [1,64]. LCA is a projectlevel tool for estimating the environmental burdens associated with materials extraction and production, construction, maintenance and rehabilitation (M\&R), transportation of materials, work zone traffic management, usage, and end-of-life phases [66]. To implement LCA in the pavement, there are different LCA tools, for example, GaBi, PaLATE, OpenLCA, and SimaPro [66,67]. According to Santos et al. [66] and Olagunju et al. [67], these LCA tools are designed to evaluate and weigh the environmental impacts of materials and production processes.

LCA allows a general methodology for recognizing procedures to reduce environmental impacts [8] of pavement by dividing its life cycle into several major phases, including material production, construction, use, maintenance and rehabilitation (M\&R), and end of life [61] by computing the probable impact [36]. Various methodologies are available for quantifying carbon emission of pavement construction worldwide, but adopting and promoting the existing tools is found to be fairly challenging due to institutional constraints [68]. Furthermore, environmental analysis conducted using qualitative rather than quantitative approaches has provided weak and unreliable results [69].

The probabilistic LCA framework takes design configuration details as input and quantifies the energy, raw materials, and emissions for the construction, maintenance, and end of life of the asphalt pavement [15]. Input data uncertainty due to experiential deviation, measurement error, data obsoleting, excessive technical differences, and data missing [60] needs to be propagated throughout the system using probability distribution techniques [70]. To encourage environmentally friendly construction, the potential environmental impact of construction works should be considered during the decision-making process in the early design phase [36].

According to Table 3, Monte Carlo analysis, polynomial regression models, probabilistic LCA, aggregated data quality indicator, and Bayesian analysis is the most common methods used in the design of pavement to consider different uncertainties in LCA. Different methods can reduce the environmental impacts of a pavement system. Among permeable pavements, warm-mix crumb rubber-modified asphalt, warm mixed asphalt-reclaimed asphalt pavement (WMA-RAP) mixtures, warm mixed asphalt (WMA), reclaimed asphalt pavement (RAP), and nano-modified bitumen can be used to enhance environmental security. The use of the existing LCA framework in the pavement is challenging because it needs extensive time and resources to gather the essential data for the analysis [7,71]. Additional challenges of LCA include data uncertainty, model uncertainty [60], incomplete inventory assessments [1], uncertainties of the potential pavement environmental impacts, prediction models, prediction of future pavement properties, current and future traffic characteristics, the extent of maintenance, and material hauling distance [16]. Since LCA outcome is extremely dependent on the steadiness of input parameters and model 
uncertainties [60], there is a need for a comprehensive approach applicable to various civil engineering works [72]. Thus, the use of a probabilistic LCA framework to measure the impact of pavement has been proposed.

Table 3. Pavement life cycle potential environmental impacts, uncertainty, and impact reduction techniques.

\begin{tabular}{|c|c|c|c|}
\hline Potential Environmental Impacts & $\begin{array}{l}\text { Uncertainty } \\
\text { Consideration }\end{array}$ & Impact Reduction & References \\
\hline $\begin{array}{l}\mathrm{CO}_{2} \text { emissions, greenhouse gas emissions, lead emissions and zinc } \\
\text { emissions, depletion of minerals and fossil fuels, depletion of the } \\
\text { ozone layer, global warming, acidification, photo-oxidant } \\
\text { formation, human toxicity, eco-toxicity, and eutrophication }\end{array}$ & Monte Carlo analysis & $\begin{array}{l}\text { using permeable } \\
\text { pavements }\end{array}$ & [64] \\
\hline $\begin{array}{l}\text { Non-carcinogenic effect, aquatic ecotoxicity, and terrestrial } \\
\text { ecotoxicity }\end{array}$ & $\begin{array}{l}\text { Polynomial } \\
\text { regression models }\end{array}$ & WMA-RAP mixtures & [73] \\
\hline $\mathrm{CO}$ and $\mathrm{SO}_{2}$ & Probabilistic LCA & RAP & [74] \\
\hline Energy consumption in asphalt mixture production & $\begin{array}{l}\text { Aggregated data } \\
\text { quality indicator }\end{array}$ & WMA, RAP & [75] \\
\hline $\mathrm{CH}_{4}$ and $\mathrm{N}_{2} \mathrm{O}$ & $\begin{array}{l}\text { Bayesian analysis of } \\
\text { parameter }\end{array}$ & $\begin{array}{l}\text { Nano-modified } \\
\text { bitumen }\end{array}$ & {$[60]$} \\
\hline Abiotic Resource Depletion Human Toxicity & - & $\begin{array}{l}\text { warm-mix crumb } \\
\text { rubber-modified } \\
\text { asphalt }\end{array}$ & [36] \\
\hline
\end{tabular}

In the proposed probabilistic life-cycle assessment framework, uncertainty quantification is a critical step required in decision-making. The enhancement of uncertainty quantification practice has introduced a scientific basis that contributed to better results in the LCA [70]. Probabilistic LCA will be carried out using Monte Carlo simulation (MCS) to assess scenario uncertainty, parameter uncertainty, variability in construction materials and methods, and the uncertainty of different sources with consideration of relative uncertainty [73]. The developed framework allows for comparing different design alternatives in terms of ecological sustainability.

The awareness of forecasting the environmental impact of construction-related activities and the need to prevent it is growing [64]. Thus, a framework useful for quantifying flexible pavement-related life cycle impacts at the design stage has been presented in this paper. The developed life-cycle assessment framework encourages an environmentally friendly construction activity by determining, at the early design phase, the potential environmental impact of the activity. However, it is difficult to acquire the data necessary to carry out the LCA before completing the design. Thus, LCA is not typically used in the design phase [36]. To overcome this limitation, a probabilistic LCA framework has been developed. The framework will be embedded in the design phase of the pavement to quantify the environmental impacts and energy consumptions in the holistic life of the pavement system. A framework for flexible pavement considers design inputs to quantify the energy consumption, amount of raw materials required, and emissions from the construction, maintenance, and end of life of the asphalt pavement [15]. The LCA framework allows an all-inclusive approach for recognizing strategies to reduce environmental influence throughout the life cycle of the pavement $[8,66]$. The developed probabilistic LCA framework is shown in Figure 3. 


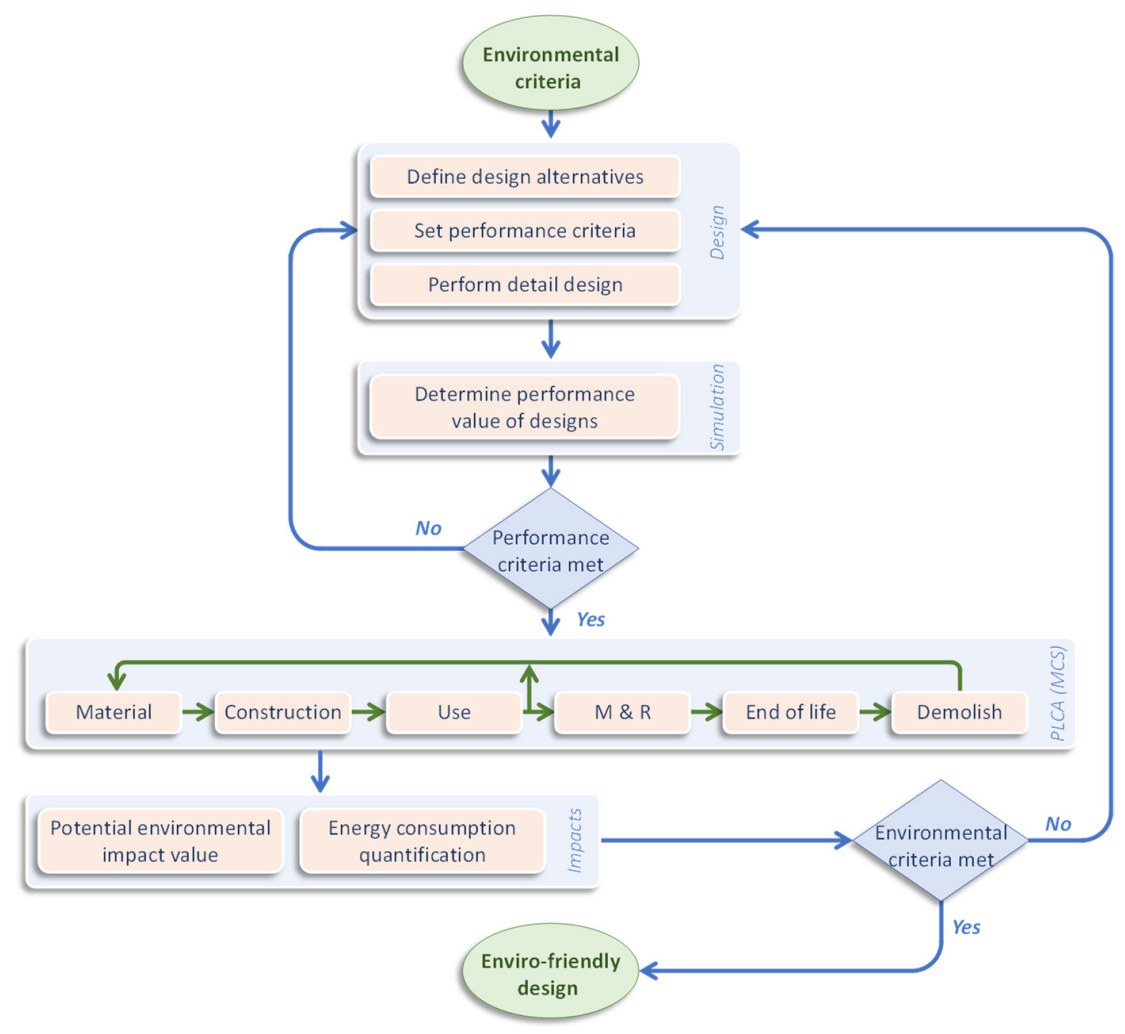

Figure 3. Probabilistic life cycle assessment framework.

The choice and use of sustainable pavement materials play an important role in environmentally-friendly pavement design. Environmentally sustainable pavement design considers drastic reduction and shift in the use of raw materials, the reduction of wastage, and replacing, renewing, and renovating of pavement materials and components. Sustainable criteria are related to material resources, energy efficiency in the manufacturing and processing of the materials, construction, and use phase of the pavement. The materials should have low environmental pollution and be less hazardous to human health Generally, environmental sustainability criteria consider

- Resource efficiency,

- Energy efficiency,

- Reducing, eliminating, or recycling wastes and ecologically unfriendly by-products,

- Designing pavements are safe and ecologically sound throughout their life cycle.

Once the environmental sustainability criteria are determined, the number of alternative designs, design components, and design period will be decided in line with environmental criteria. The performance of the design will be evaluated by a simulation to check that the criteria have been met. If the performance did not meet the defined target, the performance redesign will be revised. Finally, probabilistic LCA will be carried out using MCS. From material acquisition to pavement demolition, life cycle quantitative environmental impact and energy consumption will be determined. If the value of environmental impact and energy consumption is satisfied, it can be said that environmental sustainability is met and the design will be environmentally sustainable; otherwise, a redesign will be required.

The life cycle impact of the pavement can be quantified by adopting LCA carbon emission quantification from Huang et al. [68]

$$
\begin{gathered}
\operatorname{LCA}_{i}=P_{1}(i)+P_{2}(i)+P_{3}(i)+P_{4}(i)+P_{5}(i) \\
P_{1}(i)=\sum_{j}\left(1+\varphi_{1}\right) * Q_{M_{j}} \times i_{f_{1}}+\sum_{j}\left(1+\varphi_{2}\right) * Q_{M_{j}} \times i_{f_{2}} \\
P_{2}(i)=\sum_{j}\left(1+\varphi_{3}\right) \times Q_{k} * i_{f_{3}}
\end{gathered}
$$




$$
\begin{gathered}
P_{3}(i)=\sum_{j}\left(1+\varphi_{4}\right) * \Delta F C_{v} * i_{f_{4}} \\
P_{4}(i)=\sum_{j}\left(1+\varphi_{5}\right) * Q_{K M} * i_{f_{5}}+\sum_{j}\left(1+\varphi_{6}\right) * Q_{M M_{j}} * i_{f_{6}}
\end{gathered}
$$

where

LCA $_{i}$ life cycle impact category $i$ (impact/design in the life cycle) impact can be any potential environmental impact as shown from Table 3 ,

$P_{1}(i)$ impact category $i$ during material extraction and production phase,

$P_{2}(i)$ impact category $i$ during the construction phase,

$P_{3}(i)$ impact category $i$ during the use phase,

$P_{4}(i)$ impact category $i$ during the maintenance phase,

$j$ type of materials,

$\varphi_{1}$ uncertainty during raw material extraction and production for initial construction,

$Q_{m_{j}}$ quantity of material (tons),

$i_{f_{1}}$ impact factors for the materials at the manufacturing stage,

$\varphi_{2}$ uncertainty during material transportation,

$i_{f_{2}}$ impact factors during the materials transportation,

$\varphi_{3}$ uncertainty during construction,

$Q_{j}$ energy consumptions during construction,

$k$ types of energy (e.g., electricity, diesel, petroleum, and gas),

$i_{f_{3}}$ factors during the construction stage,

$\varphi_{4}$ uncertainty extra fuel consumption,

$\triangle F C_{v}$ extra fuel consumption,

$i_{f_{4}}$ impact factor for extra fuel consumption,

$\varphi_{5}$ uncertainty during raw material extraction and production for maintenance,

$Q_{K M}$ energy consumptions during the maintenance phase,

$i_{f_{5}}$ impact factors for energy consumptions during the maintenance phase,

$\varphi_{6}$ uncertainty during material transportation for maintenance work,

$Q_{M M_{j}}$ quantity of material for maintenance work (tons),

$i_{f_{6}}$ impact factors during maintenance work.

Pavement has different impact categories during its life cycle phase, so each phase (from Figure 3) impact will be computed during design phased using mote carol simulation at the design phase of the pavement then the sum of individual phase impact will be over all impact of the pavement during its life cycle.

\subsection{Life Cycle Cost Analysis Framework}

In LCCA, the agency cost and vehicle operating cost have been considered in the determination of the optimal timing for maintenance treatments [76]. The research focused on optimizing agency expenses for pavement life cycle while maximizing pavement quality [77]. Hence, pavement construction and asset management strategies need to be assessed from design to service cost aspects to arrive at the best value choice [78]. The result of LCCA is dependent on the deterioration procedure, so a consistent performance forecasting model remains a key aspect in the effective execution of real-world LCCA [79]. Pavement performance indicators include rutting, roughness, longitudinal cracking, transverse cracking, and alligator cracking $[80,81]$.

Life cycle cost includes initial construction costs, maintenance and rehabilitation costs (i.e., agency costs), and sometimes user costs associated with vehicle operations [82]. The entire agency and user costs should be properly considered throughout the analysis period [20]. LCCA explicitly accounts for the differences in material production cost, the cost related to pavement life-cycle performance, maintenance triggers, and maintenance effects, vehicle fuel consumption cost, and delay cost $[80,83]$. To evaluate long-term alternative pavement design, comprehensive agency cost and user-related cost should be considered [84]. 
LCCA is an efficient method for determining the monetary influence of possible modifications in design, construction, and materials [85]. Pavement engineers and managers mainly use LCCA to make a decision [30]. LCCA is a framework to evaluate the most economically practical investment from established options over their respective lifetimes [25]. To evaluate long-term alternative pavement design investment options, the inputs are very robust [84]. Further, all the input factors in a highway project valuation modeling have uncertainties and use the technical aspects of pavement engineering in the calculations to achieve real value for the projects [86]. There are several approaches used in performing LCCA including (i) probabilistic approach which addresses the variability and uncertainty associated with the LCCA input parameters including activity cost and timing and discount rate [18], (ii) probabilistic simulation-optimization LCCA approach [82], (iii) deterministic and probabilistic approaches [87], and (iv) probabilistic and fuzzy approaches [88]. Since the result of LCCA depends on the deterioration procedure, a consistent performance forecasting model remains a key parameter in the effective execution of real-world LCCA [79]. However, experts are frequently challenged with substantial uncertainties in estimating the future costs, in both short and long terms. This uncertainty promotes a probabilistic perspective of LCCA [25]. Therefore, a probabilistic LCCA framework has been developed as shown in Figure 4.

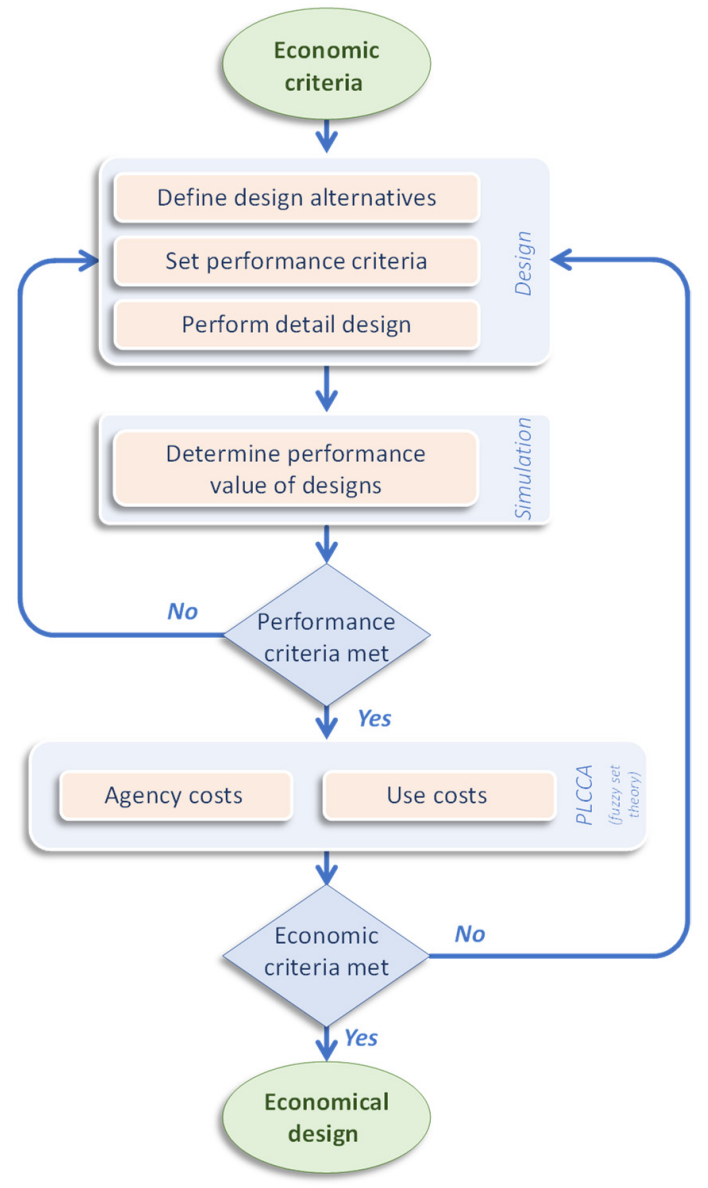

Figure 4. Probabilistic life cycle cost analysis framework.

The LCCA explicitly accounts for the alterations in material production costs, pavement life-cycle performance, maintenance triggers, maintenance effects, vehicle fuel consumption costs, and work zone user delay costs [80,81]. Probabilistic addresses the variability and uncertainty associated with the LCCA input parameters, including activity cost, activity timing, and discount rate [18]. According to Table 4, in LCCA both agency cost and user cost can be determined by probabilistic MCS or fuzzy set theory technique. 
Table 4. Life cycle cost analysis techniques and cost categories.

\begin{tabular}{ccc}
\hline Cost Considered & Techniques & References \\
\hline Agency and user cost & Probabilistic Monte Carlo simulations & {$[89]$} \\
Agency and user cost & Fuzzy set theory & {$[90]$} \\
Agency cost & Probabilistic Monte Carlo simulations & {$[82]$} \\
\hline
\end{tabular}

The probabilistic LCCA framework will consider uncertainty in agency and user's costs to select the best available options in terms of cost-efficiency. To characterize uncertainties from different sources, fuzzy set theory can be implemented in LCCA. This approach is based on how humans think and operate by turning human thoughts into mathematical functions. Fuzzy set theory has the capability of representing uncertain information [86]. It allows for the performance of mathematical operations and algorithmic applications in fuzzy space and thereby presents results that are nearer to those derived from the way the human mind operates. Bagdatli [90] provided algorithms to use the fuzzy logic-based approach in LCCA modeling of road pavements.

LCCA compares the long-term economic impacts of pavements under the future environment [81]. Economic sustainability indicators include maximizing reliability and minimizing construction, maintenance, user, and operating costs. These economic criteria could be achieved by innovations in design, construction, and material utilization. After determining the economic criteria, the number of alternative designs, design components, and design period will be decided in line with the economic criteria. At this stage, performance criteria will also be set. For each defined design alternative, a detailed design configuration (e.g., layers thickness and arrangement, and amount of traffic to support) will be determined. Performance simulation will be carried out to predict the lifetime performance value of the design alternatives. If the lifetime performance of the design has met the required performance criteria, then the required performance is satisfied, if not the design configuration is modified. Lastly, probabilistic LCCA will be carried out using fuzzy set theory. Both agency and user costs related to the pavement will be quantified. If the value of life cycle cost meets the economic criteria, then an economic design has been achieved. Otherwise, another design alternative should be sought until the economic criteria are satisfied.

Probabilistic life cycle cost can be calculated as follow

$$
\operatorname{LCC}_{a}(t)=\operatorname{ICC}(t) *\left(1+\varphi_{7}\right)+\sum_{\eta=1}^{N}\left\{\left[\left(1+\varphi_{8}\right) * F C_{\eta}(i)\right]+\frac{1}{(1+r)^{y}}\right\}
$$

where

$L C C_{a}(t)$ life cycle cost of pavement design alternative $a$ at time $t$ (in $\$$ ),

$\operatorname{ICC}(t)$ initial construction cost in monetary units for alternative design $a$ (in \$),

$\varphi_{7}$ uncertainty for an initial construction cost of pavement design alternative $a$, $\varphi_{8}$ uncertainty future costing factor for alternative design config $a$,

$N$ total category of future costing factor events for design alternative $a$,

$\eta$ future costing factor event for design alternative $a$,

$F$ future costing for costing factor event $\eta$ (in \$),

$y$ year at which future costing factor event $\eta$ will occur for design configuration $a$ (years), $r$ discount rate $(\%)$.

Pavement lifecycle user and agency cost will be computed using fuzzy set theory at the design phase as indicated from Figure 4.

\subsection{Sustainability Framework}

Sustainable pavement is durable and robust which can meet the technical requirements for a sound road, preserves and restores ecosystem related to the road, makes effective use of natural, financial, and human resources. Design can influence the sustainability of the pavement in terms of life cycle costs, performance, and the materials used. Thus, the 
need to minimize the use of scarce primary resources is becoming urgent in the pavement industry [27]. Considering sustainability into pavement design provides various criteria for assessing pavement investment decisions, against environmental, social, and economic impacts [34].

Constraints in budgets, rapid world population growth, and an increase in travel demand have placed a significant burden on pavement systems. Hence, pavement engineers are being forced to use sustainable criteria [31]. Several issues including augmented traffic flow, risky situation events, scarcity of quality pavement materials, and inadequate resources have triggered a declining trend in the quality of the pavement. Conventional pavement designs are not adequate in providing solutions that meet the diverse sustainability challenges. Furthermore, design variables and constraints are subject to uncertainties. The absence of a comprehensive sustainable flexible pavement design framework that considers the uncertainties of the design parameters, extreme events with high impacts, and premature failure of road infrastructures is the main challenge [91].

Sustainable pavement design criteria is a step up aiming at maintaining a balance between the natural and built environments [92]. It has become the focus of modern infrastructure design [93] by promoting the main criteria for a sustainable pavement. The criteria are the use of rapidly renewable resources, recycled materials, resource assurance for the next generation, the efficient uses of resources over the life of the infrastructure, reducing greenhouse gas emissions, ensuring a high level of user comfort and safety, material conservation, and resource efficiency. By considering these criteria, the sustainability of road construction contributes to the environmental wellbeing and economic and social developments in a country [29]. Pavement engineers need access to tools that enable them to design pavement systems that can produce reliable and sustainable solutions under a set of complex scenarios and uncertainties. Hence, this paper presents a comprehensive sustainable framework by integrating the calculus of a resilience framework, probabilistic LCA framework, and probabilistic LCCA framework into one single framework. Multiobjective optimization values of individual sustainability pillars are considered in the fuzzy composite program to determine the sustainability index. The overall framework is depicted in Figure 5.

The proposed pavement resilience framework, PLCA framework, and PLCCA framework were developed based on resilience, environmental, and economic criteria as design prerequisites at the initial stage of pavement design. The sustainability criteria, resilience, environmental and economic criteria, have been set in advance to define the alternative designs. For the defined design alternatives, performance criteria will be determined, and detailed pavement design will be selected using pavement design questions. The performance of the proposed design will be evaluated using MATLAB Simulink programming simulation tools. In the simulation process, the conventional lifetime reliability of the pavement will be evaluated based on the set performance criteria. The design that meets the performance criteria will go for further evaluation of resilience, PLCCA, and PLCCA using multi-objective fussy composite programming. To evaluate the sustainability criteria, the design which meets all resilience, environmental and economic criteria will be considered as sustainable design. Those that do not meet the sustainability criteria will require a redesign until sustainability criteria are met. Simultaneous, consideration of resilience, PLCA, and PLCCA within the single framework at the design stage to evaluate pavement sustainability will make the proposed framework unique. Thus, the framework could be considered in the design phase to ensure sustainable pavement. The proposed framework will enable highway agencies to compare alternative pavement designs based on sustainability criteria once individual sustainability pillars are quantified. 


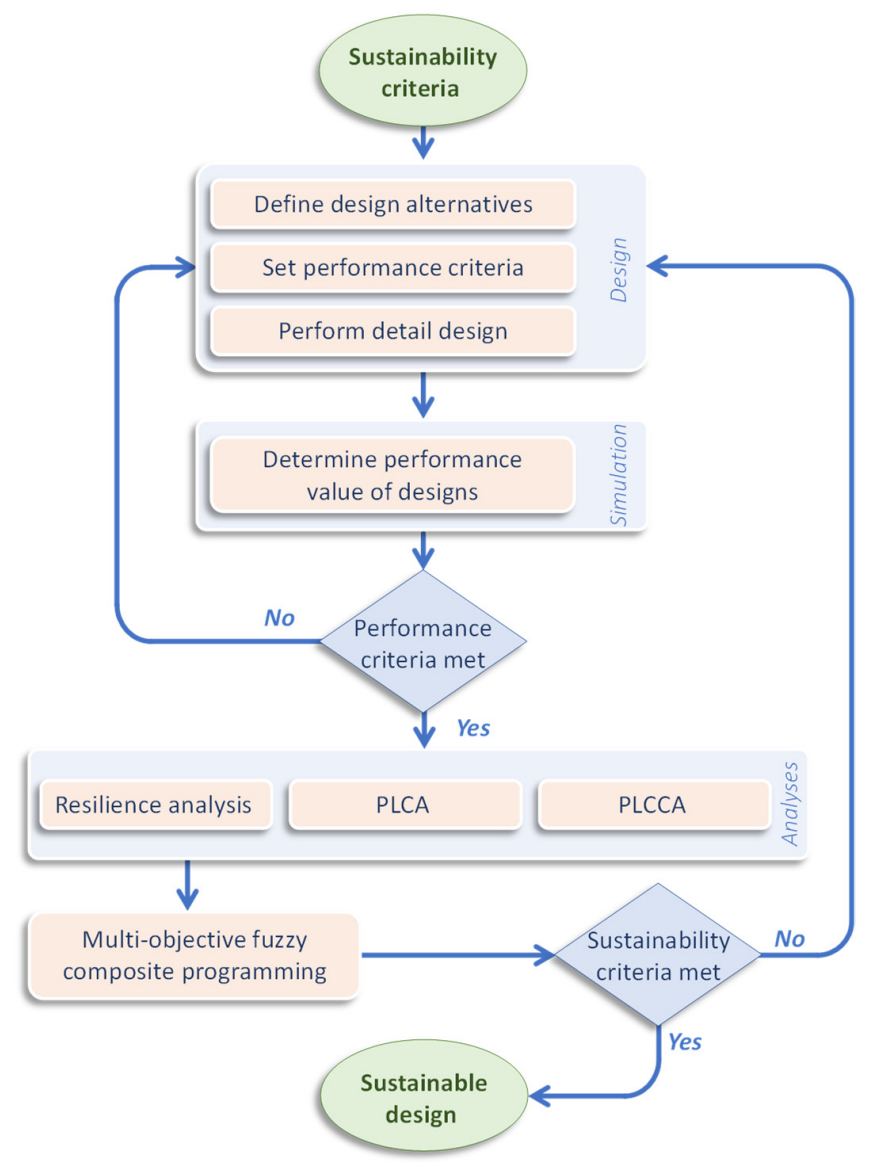

Figure 5. Framework for a design of sustainable flexible pavement.

According to Table 5, in LCA, LCCA, and PMS frameworks, decision-support tools, rating and certification tools, calculators, guidelines, and decision-support tools are used as sustainability tools. Concerning the pavement sustainability index framework, environmental, social, and economic impacts of a system are used to measure sustainability. Green Leadership In Transportation Environmental Sustainability (Green LITES), Green roads, Illinois livability and sustainable transportation (I-LAST), INVEST, and STARS are used as sustainability certification in a pavement.

Table 5. Sustainability framework, rating system, indicators, and uncertainty.

\begin{tabular}{|c|c|c|c|c|}
\hline Framework & $\begin{array}{l}\text { Sustainability Tool } \\
\text { Category/Indicators }\end{array}$ & $\begin{array}{l}\text { Uncertainty } \\
\text { Consideration }\end{array}$ & $\begin{array}{l}\text { Rating Systems } \\
\text { and } \\
\text { Certification } \\
\text { Tools }\end{array}$ & References \\
\hline $\begin{array}{c}\text { LCA, } \\
\text { LCCA, } \\
\text { PMS }\end{array}$ & $\begin{array}{l}\text { Decision-support } \\
\text { tools, rating and } \\
\text { certification tools, } \\
\text { calculators, and } \\
\text { guidelines }\end{array}$ & $\begin{array}{l}\text { Scenario uncertainty, } \\
\text { variability in } \\
\text { construction materials } \\
\text { and methods, } \\
\text { parameter uncertainty, } \\
\text { and use Monte Carlo } \\
\text { analysis }\end{array}$ & $\begin{array}{l}\text { Green LITES, } \\
\text { Green roads, } \\
\text { I-LAST, INVEST, } \\
\text { and STARS }\end{array}$ & [6] \\
\hline $\begin{array}{l}\text { Pavement } \\
\text { sustainabil- } \\
\text { ity }\end{array}$ & $\begin{array}{c}\text { Environmental impact } \\
\text { Social impact }\end{array}$ & & & [26] \\
\hline $\begin{array}{l}\text { index } \\
\text { Frame- } \\
\text { work }\end{array}$ & Economic impact & & & \\
\hline
\end{tabular}




\section{Discussion}

There are no known resilience threshold values for flexible pavement, which remains an ongoing challenge to researchers [40]; and no clear methodology was found to quantify resilience both in terms of operational and infrastructure integrity [53]. Therefore, a resilience pavement framework that can be used as a lens for sustainability has been developed. RA is an advanced technique of modeling that predicts the pavement structural conditions and acts proactively to maintain pavement functionality [45]. Thus, to counter the effect at the design stage, resilience can be analyzed using different approaches such as graph theory, optimization techniques, and simulation [14].

The use of LCA in the pavement is challenging because it needs extensive time and resources to gather the essential data for the analysis [7,71]. Various methodologies for quantifying carbon emission of pavement construction are available globally, but adopting and promoting the existing tools is found to be fairly challenging due to institutional constraints [68]. So there is a need for a comprehensive approach that could apply to all pavement projects [72]. Thus, the proposed probabilistic life-cycle assessment framework allows for comparing different design alternatives in terms of ecological sustainability. The LCA framework allows an all-inclusive approach that recognizes strategies to reduce environmental influence throughout the life cycle of pavements $[8,66]$.

The result of LCCA is dependent on the deterioration procedure, so a consistent performance forecasting model remains a key aspect in the effective execution of the real-world LCCA [79]. To determine LCCA, probabilistic approach [18], probabilistic simulation-optimization LCCA approach [82], deterministic and probabilistic approaches LCCA approach [87], and probabilistic and fuzzy approaches [88] can be used.

Sustainable pavement design has become the focus of modern design [93]. Thus, this paper presents a comprehensive sustainable framework by integrating the calculus of a resilience framework, probabilistic LCA framework, and probabilistic LCCA framework into one single framework.

\section{Conclusions}

\subsection{Resilience, Life Cycle Assessment, and Life Cycle Cost Analysis}

There is inconsistency in the sustainability framework for the design and analysis of flexible pavement that involves a comprehensive assessment of sustainability in the design phase. To address this gap, the resilience analysis framework, probabilistic life cycle assessment framework, and probabilistic life cycle cost analysis framework were independently developed as pillars of sustainability. Then, these individual frameworks were integrated into a single framework to establish a comprehensive sustainable flexible pavement framework that can evaluate the sustainability of the pavement at its design phase. Therefore, the ultimate purpose of this research was to propose an integrated framework that can be used for a combined assessment of sustainability in the design phase of flexible pavement.

In the developed framework, the probabilities of extreme event occurrence and impact will be used in defining the resilience criteria to be used at the initial stage of pavement design. The design will be based on anticipated future traffic load situations and local context of susceptibility and exposure to extreme events; thereby, the resilience level of the design can be evaluated using machine learning techniques (artificial neural networks). The design that meets the resilience criteria will be considered as resilient design; otherwise, the preset resilience criteria will be redesigned. The resilient design, based on its functional performance, will be expected to exhibit high robustness, redundancy, rapid recovery, and resourcefulness. The final goal of this framework is to produce resilient designs that have a low probability of failure and short recovery time. Since climate change is inevitable, a resilience framework can be used as a lens for sustainability. Thus, resilience analysis is an indispensable part of pavement design.

In regard to pavement design parameters and LCA features, lack of uncertainty considerations, homogeneity, and transparency of parameters have been barriers for a 
harmonized application of LCA. So, in the developed PLCA framework, resource efficiency and energy efficiency will be considered as environmental criteria at the onset of the pavement design. The design will be evaluated based on the environmental criteria using Monte Carlo analysis. The design that meets the environmental criteria will be considered as environmentally friendly design; otherwise, the pavement will be redesigned until the criteria are met. Pavement material selection plays an important role in the design of environmentally friendly pavement. Thus, PLCA could be considered in the design phase to ensure the construction of environmentally friendly pavement. The proposed PLCA framework allows highway agencies to compare alternative pavement designs based on the environmental design criteria.

In the developed PLCCA framework, maximizing reliability and minimizing agency and user costs are used to define the economic criteria for the pavement design. Thus, in this framework the design will be evaluated based on the economic criteria, using fuzzy set theory. The design that meets the economic criteria will be considered as economical design; otherwise, a redesign will be required until the criteria are met. Thus, PLCCA could be considered in the design phase to ensure economically sound pavement construction. The proposed PLCCA framework allows highway agencies to compare alternative designs based on economic criteria.

\subsection{Sustainable Framework}

To quantify sustainability in flexible pavements, several tools were utilized. For instance, LCA is extensively applied to evaluate the environmental impacts of pavement options, resilience-based road network design, and analysis to have open accessibility of surface transportation under all-weather conditions. LCCA is an efficient method for determining the monetary influence of possible modifications in design, construction, and materials. Thus, a framework for use at the design phase of a sustainable flexible pavement was developed. The framework integrates resilience, economic and environmental sustainability frameworks. It can be used by pavement engineers as a guide to compare alternative design candidates by combining PLCCA, PLCA, and RA. The optimum design configuration will be selected based on sustainability key performance evaluation criteria. The fuzzy set theory for composite programming will be used to transform the concepts of comprehensive sustainability into practical design criteria and put them into practice. This is concluded by the selection of the optimum sustainable pavement alternatives.

Author Contributions: Conceptualization, E.A., T.G. and S.E.-O.; methodology, E.A., T.G. and S.E.-O.; validation, E.A., T.G. and S.E.-O.; formal analysis, E.A., T.G. and S.E.-O.; investigation, E.A., T.G. and S.E.-O.; writing—original draft preparation, E.A.; writing—review and editing, E.A., T.G. and S.E.-O.; visualization, E.A. and S.E.-O.; supervision, T.G.; project administration, T.G. and S.E.-O.; funding acquisition, S.E.-O. All authors have read and agreed to the published version of the manuscript.

Funding: This research was funded by the Ministry of Science and Higher Education, The Federal Democratic Republic of Ethiopia Grant No. 23A742. Any opinions, findings, and conclusions or recommendations expressed in this material are those of the author(s) and do not necessarily reflect the views of the Ministry of Science and Higher Education.

Institutional Review Board Statement: Not applicable.

Informed Consent Statement: Not applicable.

Data Availability Statement: Data sharing not applicable. No new data were created or analyzed in this study. Data sharing is not applicable to this article.

Acknowledgments: We would also like to thank the Jimma University/Jimma Institute of Technology for extending their support to this research. A heartfelt thank you goes to Professor Sanjaya Senadheera on his assistance with the initial concept. We also thank the anonymous reviewers for their constructive feedback which greatly improved the manuscript. 
Conflicts of Interest: The authors declare no conflict of interest. The funders had no role in the design of the study; in the collection, analyses, or interpretation of data; in the writing of the manuscript, or in the decision to publish the results.

\section{References}

1. Chong, D.; Wang, Y. Impacts of flexible pavement design and management decisions on life cycle energy consumption and carbon footprint. Int. J. Life Cycle Assess. 2017, 22, 952-971. [CrossRef]

2. Ruiz, A.; Guevara, J. Environmental and Economic Impacts of Road Infrastructure Development: Dynamic Considerations and Policies. J. Manag. Eng. 2020, 36, 04020006. [CrossRef]

3. Zulu, K.; Singh, R.P.; Shaba, F.A. Environmental and economic analysis of selected pavement preservation treatments. Civ. Eng. J. 2020, 6, 210-224. [CrossRef]

4. France-Mensah, J.; O'Brien, W.J. Developing a Sustainable Pavement Management Plan: Tradeoffs in Road Condition, User Costs, and Greenhouse Gas Emissions. J. Manag. Eng. 2019, 35, 04019005. [CrossRef]

5. Van Wijk, I.; Williams, D.J.; Serati, M. Development and Application of Sustainability Models for Unsealed Road Pavements. Transp. Res. Rec. 2017, 2657, 89-98. [CrossRef]

6. Babashamsi, P.; Md Yusoff, N.I.; Ceylan, H.; Md Nor, N.G.; Jenatabadi, H.S. Sustainable development factors in pavement life-cycle: Highway/airport review. Sustainability 2016, 8, 248. [CrossRef]

7. Subedi, S.; Hassan, M.M.; Nie, Q.; Talaat Soliman, N.S.; Gaspard, K.; Rupnow, T. Decision-Making Tool for Incorporating Cradle-to-Gate Sustainability Measures into Pavement Design. J. Transp. Eng. Part B Pavements 2018, 144, 04018051. [CrossRef]

8. Yang, S.H.; Liu, J.Y.H.; Tran, N.H. Multi-criteria life cycle approach to develop weighting of sustainability indicators for pavement. Sustainability 2018, 10, 2325. [CrossRef]

9. Sun, W.; Lu, G.; Ye, C.; Chen, S.; Hou, Y.; Wang, D.; Wang, L.; Oeser, M. The State of the Art: Application of Green Technology in Sustainable Pavement. Adv. Mater. Sci. Eng. 2018, 2018, 9760464. [CrossRef]

10. Pouranian, M.R.; Shishehbor, M. Sustainability assessment of green asphalt mixtures: A review. Environments 2019, 6, 73. [CrossRef]

11. Aurangzeb, Q.; Al-Qadi, I.L. Asphalt pavements with high reclaimed asphalt pavement content: Economic and environmental perspectives. Transp. Res. Rec. 2014, 2456, 161-169. [CrossRef]

12. Ayyub, B.M. Practical Resilience Metrics for Planning, Design, and Decision Making. ASCE ASME J. Risk Uncertain. Eng. Syst. Part A Civ. Eng. 2015, 1, 04015008. [CrossRef]

13. Knott, J.F.; Jacobs, J.M.; Sias, J.E.; Kirshen, P.; Dave, E.V. A framework for introducing climate-change adaptation in pavement management. Sustainability 2019, 11, 4382. [CrossRef]

14. Hosseini, S.; Barker, K. Modeling infrastructure resilience using Bayesian networks: A case study of inland waterway ports. Comput. Ind. Eng. 2016, 93, 252-266. [CrossRef]

15. Butt, A.A.; Birgisson, B.; Kringos, N. Considering the benefits of asphalt modification using a new technical life cycle assessment framework. J. Civ. Eng. Manag. 2016, 22, 597-607. [CrossRef]

16. Bryce, J.; Katicha, S.; Flintsch, G.; Sivaneswaran, N.; Santos, J. Probabilistic life-cycle assessment as network-level evaluation tool for use and maintenance phases of pavements. Transp. Res. Rec. 2014, 2455, 44-53. [CrossRef]

17. Wang, Z.; Wang, H. Life-cycle cost analysis of optimal timing of pavement preservation. Front. Struct. Civ. Eng. 2017, 11, 17-26. [CrossRef]

18. Llopis-Castelló, D.; García-Segura, T.; Montalbán-Domingo, L.; Sanz-Benlloch, A.; Pellicer, E. Influence of pavement structure, traffic, and weather on urban flexible pavement deterioration. Sustainability 2020, 12, 9717. [CrossRef]

19. Yodo, N.; Wang, P. Resilience Modeling and Quantification for Engineered Systems Using Bayesian Networks. J. Mech. Des. Trans. ASME 2016, 138, 031404. [CrossRef]

20. Okte, E.; Al-Qadi, I.L.; Ozer, H. Effects of Pavement Condition on LCCA User Costs. Transp. Res. Rec. 2019, 2673, 339-350. [CrossRef]

21. Gudipudi, P.P.; Underwood, B.S.; Zalghout, A. Impact of climate change on pavement structural performance in the United States Transp. Res. Part D Transp. Environ. 2017, 57, 172-184. [CrossRef]

22. Praticò, F.G.; Giunta, M.; Mistretta, M.; Gulotta, T.M. Energy and environmental life cycle assessment of sustainable pavement materials and technologies for urban roads. Sustainability 2020, 12, 704. [CrossRef]

23. Hoxha, E.; Vignisdottir, H.R.; Barbieri, D.M.; Wang, F.; Bohne, R.A.; Kristensen, T.; Passer, A. Life cycle assessment of roads: Exploring research trends and harmonization challenges. Sci. Total Environ. 2021, 759, 143506. [CrossRef]

24. Yang, R.; Al-Qadi, I.L.; Ozer, H. Effect of Methodological Choices on Pavement Life-Cycle Assessment. Transp. Res. Rec. 2018, 2672, 78-87. [CrossRef]

25. Swei, O.; Gregory, J.; Kirchain, R. Probabilistic life-cycle cost analysis of pavements: Drivers of variation and implications of context. Transp. Res. Rec. 2015, 2523, 47-55. [CrossRef]

26. Obazee-Igbinedion, S.O.; Owolabi, O. Pavement sustainability index for highway infrastructures: A case study of Maryland. Front. Struct. Civ. Eng. 2018, 12, 192-200. [CrossRef]

27. Bavandpour, M. Evaluation of the life shortening of flexible pavements. J. Fundam. Appl. Sci. 2017, 9, 470. [CrossRef] 
28. Plati, C. Sustainability factors in pavement materials, design, and preservation strategies: A literature review. Constr. Build. Mater. 2019, 211, 539-555. [CrossRef]

29. El-Hakim, M.Y.; Tighe, S.L. Sustainability of perpetual pavement designs: Canadian perspective. Transp. Res. Rec. 2012, 2304, 10-16. [CrossRef]

30. Umer, A.; Hewage, K.; Haider, H.; Sadiq, R. Sustainability evaluation framework for pavement technologies: An integrated life cycle economic and environmental trade-off analysis. Transp. Res. Part D Transp. Environ. 2017, 53, 88-101. [CrossRef]

31. Anastasio, S.; De Visscher, J.; Wayman, M.; Bueche, N.; Hoff, I.; Maeck, J.; Vanelstraete, A.; Vansteenkiste, S.; Schobinger, B. Standardization of the Environmental Information for Asphalt Technologies. Transp. Res. Procedia 2016, 14, 3542-3551. [CrossRef]

32. Corriere, F.; Rizzo, A. Sustainability in Road Design: A Methodological Proposal for the Drafting of Guideline. Procedia Soc. Behav. Sci. 2012, 53, 39-48. [CrossRef]

33. Ghimire, S.R.; Johnston, J.M. A modified eco-efficiency framework and methodology for advancing the state of practice of sustainability analysis as applied to green infrastructure. Integr. Environ. Assess. Manag. 2017, 13, 821-831. [CrossRef] [PubMed]

34. Hasan, U.; Whyte, A.; Al Jassmi, H. Critical review and methodological issues in integrated life-cycle analysis on road networks. J. Clean. Prod. 2019, 206, 541-558. [CrossRef]

35. Jiang, R.; Wu, P. Estimation of environmental impacts of roads through life cycle assessment: A critical review and future directions. Transp. Res. Part D Transp. Environ. 2019, 77, 148-163. [CrossRef]

36. Park, J.Y.; Kim, B.S. Life-cycle Assessment-based Environmental Impact Estimation Model for Earthwork-type Road Projects in the Design Phase. KSCE J. Civ. Eng. 2019, 23, 481-490. [CrossRef]

37. Moher, D.; Liberati, A.; Tetzlaff, J.; Altman, D.G.; Altman, D.; Antes, G.; Atkins, D.; Barbour, V.; Barrowman, N.; Berlin, J.A.; et al. Preferred reporting items for systematic reviews and meta-analyses: The PRISMA statement. PLoS Med. 2009,6, e1000097. [CrossRef] [PubMed]

38. Templier, M.; Paré, G. Transparency in literature reviews: An assessment of reporting practices across review types and genres in top IS journals. Eur. J. Inf. Syst. 2018, 27, 503-550. [CrossRef]

39. Faber, M.H.; Qin, J.; Miraglia, S.; Thöns, S. On the Probabilistic Characterization of Robustness and Resilience. Procedia Eng. 2017, 198, 1070-1083. [CrossRef]

40. Tonn, G.; Czajkowski, J.; Kunreuther, H.; Angotti, K.; Gelman, K. Measuring Transportation Infrastructure Resilience: Case Study with Amtrak. J. Infrastruct. Syst. 2020, 26, 05020001. [CrossRef]

41. Berkeley, A.R.; Wallace, M.; COO, C. A Framework for Establishing Critical Infrastructure Resilience Goals: Final Report and Recommendations. Final Rep. Recomm. Counc. 2010, 18-21.

42. Sharma, N.; Tabandeh, A.; Gardoni, P. Resilience analysis: A mathematical formulation to model resilience of engineering systems. Sustain. Resilient Infrastruct. 2017, 9689, 1-19. [CrossRef]

43. Hossain, N.U.I.; Jaradat, R.; Hosseini, S.; Marufuzzaman, M.; Buchanan, R.K. A framework for modeling and assessing system resilience using a Bayesian network: A case study of an interdependent electrical infrastructure system. Int. J. Crit. Infrastruct. Prot. 2019, 25, 62-83. [CrossRef]

44. Isailović, I.; Wistuba, M.P.; Falchetto, A.C. Experimental study on asphalt mixture recovery. Mater. Struct. Constr. 2017, 50, 196. [CrossRef]

45. Plati, C.; Georgiou, P.; Papavasiliou, V. Simulating pavement structural condition using artificial neural networks. Struct. Infrastruct. Eng. 2016, 12, 1127-1136. [CrossRef]

46. Henning, T.F.P. Integrating Climate Change into Road Asset Management. Integr. Clim. Chang. Road Asset Manag. 2017. [CrossRef]

47. Abimbola, M.; Khan, F. Resilience modeling of engineering systems using dynamic object-oriented Bayesian network approach. Comput. Ind. Eng. 2019, 130, 108-118. [CrossRef]

48. Harshan, R.; Glen, Z.; Michael, M. APEGBC professional practice guidelines-developing climate change-resilient designs for highway infrastructure in British Columbia (Interim). Proc. Annu. Conf. Can. Soc. Civ. Eng. 2017, 2017, 90-99.

49. Abkowitz, M.; Camp, J.; Dundon, L. Assessing the Vulnerability of Tennessee Transportation Assets to Extreme Weather. In Proceedings of the 8th Annual Intermodal Conference, Memphis, TN, USA, 7 October 2014 ; p. 49.

50. Elshaer, M. Assessing the Mechanical Response of Pavements during and after Flooding. Ph.D. Dissertation, University of New Hampshire, Durham, NH, USA, 2017.

51. Douglas, E.; Jacobs, J.; Hayhoe, K.; Silka, L.; Daniel, J.; Collins, M.; Alipour, A.; Anderson, B.; Hebson, C.; Mecray, E.; et al. Progress and challenges in incorporating climate change information into transportation research and design. J. Infrastruct. Syst. 2017, 23, 04017018. [CrossRef]

52. Wisetjindawat, W.; Kermanshah, A.; Derrible, S.; Fujita, M. Stochastic modeling of road system performance during multihazard events: Flash floods and earthquakes. J. Infrastruct. Syst. 2017, 23, 04017031. [CrossRef]

53. Panteli, M.; Mancarella, P.; Trakas, D.N.; Kyriakides, E.; Hatziargyriou, N.D. Metrics and Quantification of Operational and Infrastructure Resilience in Power Systems. IEEE Trans. Power Syst. 2017, 32, 4732-4742. [CrossRef]

54. States, U.; Qiao, Y.; Santos, J.; Stoner, A.M.K.; Flinstch, G. Climate change impacts on asphalt road pavement construction and maintenance: An economic life cycle assessment of adaptation measures in the State of Virginia, USA. J. Ind. Ecol. 2020, 2005, 342-355. [CrossRef]

55. Ayar, P.; Moreno-Navarro, F.; Sol-Sánchez, M.; Rubio-Gámez, M.C. Exploring the recovery of fatigue damage in bituminous mixtures: The role of rest periods. Mater. Struct. Constr. 2018, 51, 25. [CrossRef] 
56. You, L.; Yan, K.; Liu, N. Assessing artificial neural network performance for predicting interlayer conditions and layer modulus of multi-layered flexible pavement. Front. Struct. Civ. Eng. 2020, 14, 487-500. [CrossRef]

57. Singhal, T.K.; Kwon, O.S.; Bentz, E.; Christopoulos, C. Development of a civil infrastructure resilience assessment framework. In Proceedings of the 13th International Conference on Applications of Statistics and Probability in Civil Engineering(ICASP13), Seoul, Korea, 26-30 May 2019; pp. 1-8.

58. Mills, B.N.; Tighe, S.L.; Andrey, J.; Smith, J.T.; Huen, K. Climate change implications for flexible pavement design and performance in Southern Canada. J. Transp. Eng. 2009, 135, 773-782. [CrossRef]

59. Tokgoz, B.E.; Gheorghe, A.V. Resilience Quantification and Its Application to a Residential Building Subject to Hurricane Winds. Int. J. Disaster Risk Sci. 2013, 4, 105-114. [CrossRef]

60. Huang, J.; Xiao, F.; Zhang, Y. Reliability evaluation of pavement life-cycle assessment model. Model. Simul. Eng. 2018, 2018, 4172519. [CrossRef]

61. Chong, D.; Wang, Y.; Dai, Z.; Chen, X.; Wang, D.; Oeser, M. Multiobjective optimization of asphalt pavement design and maintenance decisions based on sustainability principles and mechanistic-empirical pavement analysis. Int. J. Sustain. Transp. 2018, 12, 461-472. [CrossRef]

62. Puccini, M.; Leandri, P.; Tasca, A.L.; Pistonesi, L.; Losa, M. Improving the environmental sustainability of low noise pavements: Comparative life cycle assessment of reclaimed asphalt and crumb rubber based warm mix technologies. Coatings $2019,9,343$. [CrossRef]

63. Erickson, L.E.; Brase, G. Paris Agreement on Climate Change. In Reducing Greenhouse Gas Emissions and Improving Air Quality; CRC Press: Boca Raton, FL, USA, 2019; pp. 11-22. [CrossRef]

64. Antunes, L.N.; Ghisi, E.; Thives, L.P. Permeable pavements life cycle assessment: A literature review. Water 2018, 10, 1575. [CrossRef]

65. Liljenström, C.; Miliutenko, S.; O’Born, R.; Brattebø, H.; Birgisdóttir, H.; Toller, S.; Lundberg, K.; Potting, J. Life cycle assessment as decision-support in choice of road corridor: Case study and stakeholder perspectives. Int. J. Sustain. Transp. 2020, 15, 678-695. [CrossRef]

66. Dos Santos, J.M.O.; Thyagarajan, S.; Keijzer, E.; Flores, R.F.; Flintsch, G. Comparison of life-cycle assessment tools for road pavement infrastructure. Transp. Res. Rec. 2017, 2646, 28-38. [CrossRef]

67. Olagunju, B.D.; Olanrewaju, O.A. Comparison of life cycle assessment tools in cement production. S. Afr. J. Ind. Eng. 2020, 31, 70-83. [CrossRef]

68. Huang, Y.; Ning, Y.; Zhang, T.; Wu, J. Measuring carbon emissions of pavement construction in China. Sustainability 2016, 8, 723. [CrossRef]

69. Cantisani, G.; Di Mascio, P.; Moretti, L. Comparative Life Cycle Assessment of lighting systems and road pavements in an Italian twin- tube road tunnel. Sustainability 2018, 10, 4165. [CrossRef]

70. Ziyadi, M.; Al-Qadi, I.L. Model uncertainty analysis using data analytics for life-cycle assessment (LCA) applications. Int. J. Life Cycle Assess. 2019, 24, 945-959. [CrossRef]

71. Trunzo, G.; Moretti, L.; D'Andrea, A. Life cycle analysis of road construction and use. Sustainability 2019, 11, 377. [CrossRef]

72. Moretti, L.; Mandrone, V.; D'Andrea, A.; Caro, S. Comparative "from cradle to gate" life cycle assessments of Hot Mix Asphalt (HMA) materials. Sustainability 2017, 9, 400. [CrossRef]

73. AzariJafari, H.; Yahia, A.; Amor, B. Assessing the individual and combined effects of uncertainty and variability sources in comparative LCA of pavements. Int. J. Life Cycle Assess. 2018, 23, 1888-1902. [CrossRef]

74. Calabi-Floody, A.T.; Valdés-Vidal, G.A.; Sanchez-Alonso, E.; Mardones-Parra, L.A. Evaluation of gas emissions, energy consumption and production costs of Warm Mix Asphalt (WMA) involving natural zeolite and Reclaimed Asphalt Pavement (RAP). Sustainability 2020, 12, 6410. [CrossRef]

75. Chong, D.; Wang, Y.; Chen, L.; Yu, B. Modeling and Validation of Energy Consumption in Asphalt Mixture Production. J. Constr. Eng. Manag. 2016, 142, 04016069. [CrossRef]

76. Liu, P.; Ravee, V.; Wang, D.; Oeser, M. Study of the influence of pavement unevenness on the mechanical response of asphalt pavement by means of the finite element method. J. Traffic Transp. Eng. Engl. Ed. 2018, 5, 169-180. [CrossRef]

77. Moreira, A.V.; Fwa, T.F.; Oliveira, J.R.M.; Costa, L. Coordination of user and agency costs using two-level approach for pavement management optimization. Transp. Res. Rec. 2017, 2639, 110-118. [CrossRef]

78. Aniekwu AN, A.H. Life Cycle Cost Analysis (Lcca) Delivery Model for an Urban Flexible Pavement. J. Civ. Environ. Eng. 2015, 5, 1. [CrossRef]

79. Han, D.; Kaito, K.; Kobayashi, K.; Aoki, K. Management scheme of road pavements considering heterogeneous multiple life cycles changed by repeated maintenance work. KSCE J. Civ. Eng. 2017, 21, 1747-1756. [CrossRef]

80. Wang, H.; Zhao, J. Development of overweight permit fee using mechanistic-empirical pavement design and life-cycle cost analysis. Transport 2016, 31, 156-166. [CrossRef]

81. Qiao, Y.; Dave, E.; Parry, T.; Valle, O.; Mi, L.; Ni, G.; Yuan, Z.; Zhu, Y. Life cycle costs analysis of reclaimed asphalt pavement (RAP) under future climate. Sustainability 2019, 11, 5414. [CrossRef]

82. Guo, F.; Gregory, J.; Kirchain, R. Probabilistic Life-Cycle Cost Analysis of Pavements Based on Simulation Optimization. Transp. Res. Rec. 2019, 2673, 389-396. [CrossRef] 
83. Qiao, Y.; Dawson, A.R.; Parry, T.; Flintsch, G.; Wang, W. Flexible pavements and climate change: A comprehensive review and implicatio. Sustainability 2020, 12, 1057. [CrossRef]

84. Lee, E.B.; Thomas, D.K.; Alleman, D. Incorporating road user costs into integrated Life-Cycle Cost Analyses for infrastructure sustainability: A case study on Sr-91 corridor improvement project (Ca). Sustainability 2018, 10, 179. [CrossRef]

85. Ozer, H.; Yang, R.; Al-Qadi, I.L. Quantifying sustainable strategies for the construction of highway pavements in Illinois. Transp. Res. Part D Transp. Environ. 2017, 51, 1-13. [CrossRef]

86. Esmaeeli, A.N.; Heravi, G. Real Options Approach versus Conventional Approaches to Valuing Highway Projects under Uncertainty. J. Constr. Eng. Manag. 2019, 145, 04019068. [CrossRef]

87. Wang, H.; Wang, Z. Deterministic and probabilistic life-cycle cost analysis of pavement overlays with different pre-overlay conditions. Road Mater. Pavement Des. 2019, 20, 58-73. [CrossRef]

88. Plebankiewicz, E.; Meszek, W.; Zima, K.; Wieczorek, D. Probabilistic and fuzzy approaches for estimating the life cycle costs of buildings under conditions of exposure to risk. Sustainability 2020, 12, 226. [CrossRef]

89. Akbarian, M.; Swei, O.; Kirchain, R.; Gregory, J. Probabilistic characterization of life-cycle agency and user costs case study of Minnesota. Transp. Res. Rec. 2017, 2639, 93-101. [CrossRef]

90. Bagdatli, M.E.C. Fuzzy Logic-Based Life-Cycle Cost Analysis of Road Pavements. J. Transp. Eng. Part B Pavements 2018, 144, 04018050. [CrossRef]

91. Asia, F.I.N. Climate and Disaster Resilient Transport System and Infrastructure Development for Nepal. 2015. Available online: https:/ / www.uncrd.or.jp/content/documents/3381Background\%20Paper\%20-EST\%20Plenary $\% 20$ Session $\% 202 \% 20$ (No.\%202).pdf (accessed on 15 December 2021).

92. Muench, S.T.; Anderson, J.L.; Hall, M.; Muench, S.T.; Anderson, J.L. Final Technical Report Greenroads: A Sustainability Performance Metric for Roadway Design and Construction by University of Washington and a Report Prepared for Transportation Northwest (TransNow) University of Washington DTRT07-G-0010 None. 2009. Available online: http:/ / depts.washington.edu/ trac/bulkdisk/pdf/725.1.pdf (accessed on 15 December 2021).

93. Thongram, S.; Rajbongshi, P. Reliability Based Deterministic Design Approach in Asphalt Pavements. J. Innov. Res. Sci. Eng. Tech 2016, 3092-3097. [CrossRef] 